\title{
Management of Dyslipidemia as a Cardiovascular Risk Factor in Individuals with Nonalcoholic Fatty Liver Disease
}

\author{
Kathleen E. Corey, MD, MPH and \\ Department of Medicine, GI Unit, Massachusetts General Hospital, Boston, MA \\ Naga Chalasani, MD \\ Department of Medicine, Indiana University School of Medicine, Indianapolis, IN
}

\begin{abstract}
Nonalcoholic fatty liver disease (NAFLD) is the most frequent cause of liver disease in the United States and is associated with an increased risk of cardiovascular disease (CVD) and cardiovascular (CV) mortality, independent of traditional cardiovascular risk factors. CVD is one of the most common causes of death among individuals with NAFLD and management of NAFLD must extend beyond liver disease to include CVD risk modification. Clinicians should assess CVD risk with the Framingham Risk Score (FRS) and screen for CVD risk factors including dyslipidemia, diabetes mellitus (DM), hypertension, tobacco use and the metabolic syndrome (MetS). CVD risk factors, particularly dyslipidemia, require aggressive medical management to reduce the high risk of CVD events and death in individuals with NAFLD.
\end{abstract}

\section{Keywords}

Dyslipidemia; Nonalcoholic fatty liver disease; Cardiovascular disease

\section{Background}

NAFLD impacts $30-40 \%$ of Americans. ${ }^{1}$ Nonalcoholic steatohepatitis (NASH), the progressive form of NAFLD, impacts $2-12 \%$ of Americans. ${ }^{2}$ NASH can lead to the development of cirrhosis and it is predicted that by 2020, NASH cirrhosis will be the leading indication for liver transplantation in the United States. ${ }^{3}$

While NASH can result in end stage liver disease, steatosis and NASH are associated with an increased risk of CVD events and death both independently and by their frequent association with the MetS, insulin resistance and dyslipidemia. ${ }^{4}$ A meta-analysis assessing the natural history of NAFD found that while NASH was associated with increased liver-

(C) 2013 The American Gastroenterological Association. Published by Elsevier Inc. All rights reserved.

Corresponding Author. Naga Chalasani, MD, Professor of Medicine and Cellular \& Integrative Physiology, Chief, Division of Gastroenterology and Hepatology, Indiana University School of Medicine, 1050 Wishard Blvd, RG 4100, Indianapolis, IN, 46202, nchalasa@iupui.edu.

Publisher's Disclaimer: This is a PDF file of an unedited manuscript that has been accepted for publication. As a service to our customers we are providing this early version of the manuscript. The manuscript will undergo copyediting, typesetting, and review of the resulting proof before it is published in its final citable form. Please note that during the production process errors may be discovered which could affect the content, and all legal disclaimers that apply to the journal pertain. 
related mortality when compared to steatosis, there was no difference in the risk of CVDrelated death between NASH and steatosis. ${ }^{4}$ Currently, CVD is the leading cause of death in individuals with NAFLD. ${ }^{5}$ Modification of CVD risk factors, particularly dyslipidemia, is necessary to decrease CVD morbidity and mortality in individuals with NAFLD. In this review, we will address the need for CVD risk stratification and outline methods for CVD risk management in individuals with NAFLD. While the breadth of data on CVD risk management in NAFLD is expanding, limitations remain. Where data are unavailable for NAFLD specifically, we have drawn from the CVD literature in the general population and in individuals with other CVD risk factors.

\section{Dyslipidemia in NAFLD}

Dyslipidemia is frequent in individuals with NAFLD. A substudy from the Multi-Ethnic Study of Atherosclerosis (MEAS) assessed the relationship between radiographically diagnosed NAFLD and dyslipidemia. ${ }^{6}$ NAFLD was independently associated with elevated triglyceride levels, increased low-density lipoprotein (LDL) particle concentration, decreased LDL particle size and decreased high-density lipoprotein (HDL) levels after controlling for insulin resistance. These findings have been replicated in individuals with NAFLD from other community cohorts and in individuals with NAFLD and DM. ${ }^{7,8}$ In addition, non-HDL-cholesterol (non-HDL-C) is increased in individuals with NASH. ${ }^{9}$ NonHDL-C is a measure of all atherogenic lipoproteins including very-low density lipoproteins (VLDL), LDL, intermediate-density lipoproteins (IDL) and Lipoprotein a (Lp(a)). ${ }^{10}$ NonHDL-C is calculated from a standard lipid panel (Non-HDL-C $=$ Total cholesterol-HDL) and guidelines cite non-HDL-C $<150 \mathrm{mg} / \mathrm{dL}$ as a secondary target for lipid lowering therapy. ${ }^{11,12}$

\section{Cardiovascular Disease and NAFLD}

CVD events are a frequent cause of morbidity and mortality in individuals with NAFLD. (Table 1) Three community-based studies have demonstrated that individuals with radiographically diagnosed NAFLD have an increased risk of CVD events and mortality compared to individuals without NAFLD. ${ }^{13-15}$ Hamaguchi et al. assessed 1637 subjects in a community-based cohort from Japan for NAFLD by ultrasonography. ${ }^{16}$ Nineteen percent of the cohort was found to have NAFLD. Cardiovascular events occurred in $5.2 \%$ of NAFLD subjects and $1.0 \%$ of non-NAFLD individuals over 5 years. $(\mathrm{p}<0.01)$ This difference remained statistically significant after adjustment for the MetS. Adams et al. found a high incidence of CV mortality in a US-based cohort. ${ }^{14}$ Four hundred twenty individuals with NAFLD were followed for a median of 7.6 years. Individuals with NAFLD had significantly increased mortality when compared to the general population with a standardized mortality ratio of 1.34 (95\% CI: 1.003-1.76). Targher et al. found that CVD events and mortality were also more common among diabetic individuals with NAFLD than diabetics without NAFLD [OR: 1.87 (95\% CI: 1.2-2.60)]. ${ }^{13}$

Histologically defined NAFLD is also associated with an increased CVD risk. Soderberg et al. performed liver biopsies in 256 subjects, 118 of whom had NAFLD which were blindly scored for steatosis and NASH. ${ }^{17}$ Individuals with NAFLD (both steatosis and NASH) had a $69 \%$ increased mortality compared with the overall population. Ekstedt et al. also found that 
individuals with NASH had increased mortality compared to the general population, a difference not seen in those with only steatosis. ${ }^{18}$ Again, CVD was the most common cause of death among individuals with NASH. Thus, individuals with both radiographically and histologically defined NAFLD are at increased risk for CVD and mortality.

\section{Cardiovascular Risk Stratification in NAFLD}

Several different methods are used in the general population to estimate CVD risk including the Framingham Risk Score (FRS). The FRS is a validated measure of cardiovascular risk in the general population. Incorporating age, gender, cholesterol, HDL, smoking status and hypertension, the FRS predicts an individual's 10-year risk of myocardial infarction or CVD death. Further, the FRS has been validated as a predictor of CVD in NAFLD and should be used to risk stratify individuals and guide treatment of risk factors including dyslipidemia. ${ }^{19}$

The MetS is frequent in individuals with NAFLD and associated with increased CVD and all-cause mortality. ${ }^{20,21}$ Therefore, assessment for the MetS is an important component of CVD risk stratification. Several definitions for MetS exist. ${ }^{22}$ The MetS as defined by the National Cholesterol Education Program (NCEP) requires the presence three or more of the following components:

1. Elevated triglycerides $(\geq 150 \mathrm{mg} / \mathrm{dL})$

2. Low HDL $(<40 \mathrm{mg} / \mathrm{dl}$ in men, $<50 \mathrm{mg} / \mathrm{dl}$ in women)

3. Elevated fasting glucose $(\geq 110 \mathrm{mg} / \mathrm{dL})$

4. Hypertension ( $\geq 130 / 85 \mathrm{~mm} \mathrm{Hg}$ or on anti-hypertensive medication)

5. Abdominal obesity (waist circumference $>102 \mathrm{~cm}$ in men, $>88 \mathrm{~cm}$ in women)

In addition to evaluation for the MetS, individuals should be evaluated for other CVD risk factors including DM which can be diagnosed using fasting glucose or glycosylated hemoglobin (HbA1C). ${ }^{23}$

Cardiac stress testing, carotid artery intima-media thickness (CIMT) assessment and coronary artery calcium (CAC) score can also add in CVD risk stratification. These modalities can be used to detect subclinical atherosclerotic disease and to predict future $\mathrm{CV}$ events. ${ }^{23-25}$ Individuals with NAFLD and elevated CVD risk have been found to have increased mean CIMT levels and elevated CAC scores suggesting the utility of these tests for risk stratification in individuals with NAFLD. ${ }^{26-28}$

\section{Management of Dyslipidemia and Cardiovascular Disease Risk in NAFLD}

Lifestyle modification, encompassing weight loss and increased physical activity, is the cornerstone of dyslipidemia management in NAFLD. However, for groups with elevated CVD risk, lifestyle modification should be accompanied by lipid lowering therapy. Guidelines set forth by the NCEP Adult Treatment Panel III provide guidance on which groups should be targeted for lipid lowering therapy and outline treatment goals. (Figure 1) ${ }^{12}$ These guidelines were not specifically designed to address dyslipidemia in individuals with NAFLD. However, they can be safely applied to individuals with NAFLD. 


\section{Dietary Modification}

Little data are available for the preferred diet for individuals with NAFLD. Two small studies have suggested that diets low in carbohydrates may result in a reduction in intrahepatic triglyceride concentration and an improvement in histologically defined NAFLD. ${ }^{29,} 30$ Low carbohydrate diets have a beneficial effect on serum lipid levels. ${ }^{31}$ For LDL lowering, the NCEP recommends a diet low in saturated fat ( $<7 \%$ of total calories) and cholesterol ( $<200 \mathrm{mg} /$ day). Plant sterols and stanols as well as increased intake of soluble fiber can also be used for dietary lipid lowering. ${ }^{12}$

Recently, a large randomized controlled trial found that subjects who consumed a Mediterranean diet had a reduction in the incidence of cardiac events compared to those receiving only advice on low fat diets. ${ }^{32}$ Limited data exist on the benefit of the Mediterranean diet in NAFLD. A trial of 12 subjects with biopsy-proven NAFLD assessed the impact of a Mediterranean diet on hepatic steatosis as assessed by magnetic resonance spectroscopy (MRS). ${ }^{33}$ Subjects undertook, in random order, 6 weeks of a low fat, high carbohydrate diet and a Mediterranean diet, separated by a 6 week wash out period. MRS steatosis decreased significantly in the group receiving the Mediterranean diet compared to the low fat, high carbohydrate diet (39\% reduction vs. $7 \%$ reduction, $\mathrm{p}=0.012)$, with no difference in weight loss between groups. This study suggests that in individuals with NAFLD the Mediterranean diet may have benefits beyond the management of dyslipidemia. However, further studies are needed before this diet can be routinely recommended.

Fructose consumption, present in processed foods and beverages, is associated with NAFLD development. ${ }^{34}$ The impact of fructose avoidance has yet to be rigorously evaluated but individuals should be advised to limit fructose consumption. The United States Dietary Guidelines for 2010 classifies fructose as an "added sugar" and recommends limiting added sugars to $\mathfrak{3}$ or less servings per day for persons on $<2,000$ calorie per day diets and $\leq$ servings per day for those on $\geq 2,000$ calorie diets.

\section{Exercise}

Regular exercise is associated with decreased triglycerides and LDL and increased HDL levels. ${ }^{35,} 36$ The NCEP recommends at least 30 minutes of moderate activity most days of the week as part of dyslipidemia management. ${ }^{12}$ Exercise is independently associated with a reduction in aminotransferase levels and hepatic triglyceride content. Sixty minutes per week of aerobic exercise decreases aminotransferase levels in subjects with NAFLD. ${ }^{37} \mathrm{~A}$ trial of subjects with NAFLD randomized to no exercise or three 30-45 minute cycling sessions weekly found that the cycling group had a significant decrease in hepatic triglyceride content and visceral adipose content without a change in overall body weight. ${ }^{38}$ Individuals with NAFLD should be advised to participate in regular, aerobic exercise.

\section{Cigarette Smoking and Alcohol Use}

Cigarette smoking is associated with increased CVD and all-cause mortality. The American College of Cardiology recommends that individuals who use tobacco receive counseling regarding smoking cessation and, if needed, referral to tobacco cessation support programs. ${ }^{23}$ Moderate alcohol intake, defined as one unit of alcohol daily for women and 2 
units daily for men, may increase HDL and apolipoprotein AI levels and decreased risk. ${ }^{12}$ Therefore, moderate alcohol use maybe helpful in reducing CVD risk.

Several studies have suggested that mild to moderate alcohol use may be protective against NAFLD development. ${ }^{39,}{ }^{40}$ However, no data exist to determine the impact of alcohol use on existing NAFLD or NASH or on the impact of alcohol use on CVD risk in individuals with NAFLD. Therefore, it is premature to recommend regular alcohol use in individuals with NAFLD.

\section{Obstructive Sleep Apnea (OSA)}

OSA is characterized by periods of apnea during sleep resulting in oxygen desaturation. Chronically, OSA increases the risk of the MetS, CVD and sudden death while treatment of OSA improves the MetS and decreases CVD mortality. ${ }^{41-4445,46}$

Several studies suggest a relationship between OSA and NAFLD. Animal models have demonstrated that mice exposed to chronic intermittent hypoxia are more likely to develop steatosis and hepatic inflammation. ${ }^{47,48}$ In humans, several studies have demonstrated a relationship between OSA and NAFLD. A study of subjects with OSA and NASH found that the oxygen desaturation index, a measure of OSA severity, was directly correlated with NASH activity score and fibrosis stage even after adjustment for insulin resistance and obesity. ${ }^{49}$ Additionally, a prospective study of individuals with radiographically defined NAFLD and OSA found that the initiation of continuous positive airway pressure (CPAP) lead to an improvement in radiographic steatosis. ${ }^{50}$ Thus, a potential link between NAFLD and OSA may exist and requires further evaluation. It would be premature to suggest that OSA treatment will improve NAFLD. However, because treatment of OSA does improve the MetS and CVD risk, screening for OSA should be considered in individuals with NAFLD.

\section{Diabetes Mellitus (DM)}

DM is associated with an increased risk of CVD. As DM is highly prevalent among individuals with NAFLD, comprehensive management is essential for CVD risk reduction. A detailed discussion of the management of DM in individuals with NAFLD is beyond the scope of this review. However, primary and secondary prevention of CVD events in individuals with DM should focus on multifactorial risk reduction, including treatment of hypertension and dyslipidemia. ${ }^{51}$ In addition, specific treatments of DM including metformin may decrease CVD events. ${ }^{52}$.

\section{Lipid Lowering Medications HMG-CoA Reductase Inhibitors}

Treatment of dyslipidemia should not be withheld in individuals with NAFLD. HMG-CoA reductase inhibitors or "statins" have a well established role in the primary and secondary prevention of CVD and individuals with NAFLD can benefit from risk reduction. ${ }^{12}$ A posthoc analysis of the Greek Atorvastatin and Coronary Heart Disease Evaluation (GREACE) study demonstrated not only that statins are safe in individuals with abnormal liver function 
tests presumably due to NAFLD but that individuals with NAFLD who received statins had a significant reduction in cardiovascular events when compared to those with NAFLD not on statins $\left(10 \%\right.$ vs. $30 \%$, p<0.0001). ${ }^{53}$ Thus, statins significantly reduce cardiovascular events in individuals with NAFLD and should be used for individuals who require lipid lowering therapy.

Early data suggest that statins may also have a specific role in the treatment of NAFLD although this requires confirmation before it can be widely applied. ${ }^{54}$ A retrospective trial of statin use in 68 individuals with histologically defined NAFLD found that those who used statins had a reduction in steatosis, despite a higher mean BMI and prevalence of DM, than those not on statins. ${ }^{55}$ In addition, the rate of fibrosis development was unexpectedly low in individuals on statin therapy. In individuals with radiographically defined NAFLD, atorvastatin has been shown in several studies to be associated with NAFLD regression. ${ }^{54,56,57}$ However, a randomized controlled trial of simvastatin in NASH therapy did not result in any histologic benefit. ${ }^{58}$ Thus, the impact of statin therapy on NAFLD remains uncertain. Importantly, however, statin hepatotoxicity was not reported in any study, reinforcing that statins are safe in individuals with NAFLD.

In addition to the role of statins in management of dyslipidemia, statins may also play a role in the prevention of hepatocellular carcinoma (HCC). ${ }^{59}$ Using a community-based cohort of individuals with DM, a nested case-control study found that a significantly fewer cases (individuals with HCC) were prescribed statins when compared to controls, suggesting a preventive role for statins in HCC development. While this study was not designed to assess HCC prevention in those with NAFLD, its finding may be applicable to those with NAFLD.

\section{Statin hepatotoxicity}

Concern for hepatotoxicity associated with statins has led to reluctance on the part of clinicians to treat dyslipidemia in individuals with NALFD. ${ }^{60}$ However, the incidence of statin-induced hepatotoxicity in those with NAFLD is vanishingly low and not greater than that experienced in the general population. ${ }^{61-64}$ Chalasani et al. evaluated the incidence of aminotransferase elevations in individuals with baseline elevations in aminotransferases (presumably secondary to NAFLD) on statins, and individuals with elevated liver enzymes who did not receive statins ${ }^{64}$ When compared to those with elevated liver enzymes not receiving statins, individuals with elevated baseline liver enzymes on statins did not have a higher incidence of either mild-moderate elevations $(4.7 \%$ vs. $6.4 \%, \mathrm{P}=0.2)$ or severe elevations $(0.6 \%$ vs. $0.4 \%, \mathrm{P}=0.6)$. These findings have been replicated in a randomized controlled trial of high dose pravastatin in individuals with chronic liver disease, predominantly from NAFLD. ${ }^{65}$

\section{Omega-3 Fatty Acids}

If additional lipid lowering therapy is needed beyond statins, omega- 3 fatty acids can be safely given in individuals with NAFLD. Omega-3 fatty acids reduce serum triglycerides by reducing VLDL secretion from hepatocytes. Omega-3 fatty acids in doses of 3-4 grams daily are associated with a decrease in triglycerides (-25-35\%) and a small increase in HDL levels (1-3\%). ${ }^{66,67}$ Early studies suggest that omega-3 fatty acids may improve 
aminotransferase levels and radiographic steatosis in individuals with NAFLD and dyslipidemia and thus, are attractive for dyslipidemia management in individuals with NASH. ${ }^{68-70}$

\section{Fibrates}

Fibrates act to lower serum triglycerides while simultaneously increasing HDL. While fibrates reduce cardiovascular mortality among individuals with elevated triglycerides they do not decrease cardiovascular mortality among individuals with normal triglyceride levels. Statins carry a risk of muscle toxicity. When statins are taken in combination with fibrates the risk is increased. This risk can be reduced by using hydrophilic statins (i.e. pravastatin, rosuvasatin, fluvastatin and atorvastatin) which have less muscle penetration than hydrophilic statins, when combination therapy with fibrates is needed. ${ }^{71,72}$

Fenofibrate has been studied in individuals with NAFLD. ${ }^{73}$ In a trial of 16 individuals with biopsy-proven NAFLD, fenofibrate $200 \mathrm{mg}$ daily for 48 weeks decreased triglyceride, glucose, gamma-glutamyl transpeptidase and alkaline phosphatase levels. In addition, a decrease in hepatocyte ballooning was seen. However, there was no significant change in steatosis grade, NASH activity score, lobular inflammation or fibrosis. However, a second trial of using clofibrate did not demonstrate a change in aminotransferase levels or histology ${ }^{74}$ No hepatotoxicity was reported from fibrates in any of the above trials. Therefore, while fibrates have not been shown to consistently improve NAFLD histologically, they do offer an effective treatment for hypertriglyceridemia and can be used safely in individuals with NAFLD.

\section{Niacin}

Niacin (nicotinic acid) lowers lipids by inhibiting the hepatic production of lipoproteins. Niacin lowers triglyceride levels and is associated with reduced cardiovascular mortality. ${ }^{75}$ However, niacin should be used with caution in DM as it can worsen glucose intolerance. As glucose intolerance may be associated with the development and progression of NAFLD, it should not be first line therapy for hypertriglyceridemia.

\section{Lipid Treatment Goals}

LDL targets designed to reduce CVD risk have been established by the National Cholesterol Education Program Adult Treatment Panel III (NCEP-ATP III). These guidelines provide individualized LDL goals based on the assessment of an individual's CVD risk factors (Figure 1).

\section{Fatty Liver and Newly Approved Lipid Lowering Agents}

Statins are effective LDL lowering agents; however, in an important subset of individuals, statins cannot lower LDL to goal treatment levels. Therefore, the search for medications to improve LDL lowering is ongoing. Two new lipid lowering agents have recently been approved. Mipomersen, an anti-sense oligonucleotide binds to and degrades hepatic apoB mRNA, decreasing circulating LDL levels. Mipomersen is effective at LDL lowering in individuals with hyperlipidemia, homozygous familial hypercholesterolemia (HFH) and 
statin intolerance. ${ }^{76-78}$ However, 11-33\% of subjects receiving mipomersen developed elevations in aminotransferase levels $>3$ times the upper limit of normal (ULN). Of the 14 individuals who developed elevations in aminotransferase levels, steatosis assessed by MRS was found in 12. Two of these individuals underwent liver biopsy. Both patients were found to have NASH, one without fibrosis and one with stage 1 fibrosis. These findings suggest an association between mipomersen use and fatty liver.

A second mechanism for lipoprotein reduction is through microsomal triglyceride transferase protein (MTTP) inhibition. MTTP catalyzes the formation of apoB containing proteins in the liver. Lomitapide, an MTTP inhibitor, has been shown in individuals with hypercholesterolemia and HFH to lower LDL levels. However, like mipomersen, lomitapide is associated with frequent elevations in aminotransferase levels and radiographic steatosis. ${ }^{79,80}$ As a result, lomitapide is approved for HFH but comes with a black box warning for hepatotoxicity. Thus, while mipomersen and lomitapide are beneficial in lowering LDL levels, they are associated with hepatotoxicity, possible NASH development and cannot currently be recommended for lipid lowering therapy in individuals with NAFLD.

\section{Future Directions}

NAFLD is a rising epidemic in the United States and is associated with cardiovascular mortality. Many individuals with NAFLD will die from CVD prior to the development of end stage liver disease. Thus, the careful management of CVD risk factors including dyslipidemia in individuals with NAFLD is essential to reduce CVD-related mortality. Gastroenterologists and hepatologists should play an active role in comprehensive CVD risk assessment including screening for dyslipidemia, DM, the MetS, cigarette smoking and alcohol use. Management of CVD risk factors should be grounded in counseling of lifestyle modification including weight loss, dietary changes and increased physical activity. When needed, this should be accompanied by lipid lowering medication with treatment goals set by the NCEP. Comprehensive evaluation and aggressive management of CVD risk factors in individuals with NAFLD could significantly decrease CVD events and deaths.

\section{Acknowledgments}

This work is in part supported by NIH K24 DK069290A (NC) and the AASLD Clinical and Translational Research Award (KEC). Dr. Chalasani served as a consultant in the past 12 months to Lilly, Salix, Aegerion, Merck, Abbott, and Mochida in the area of drug hepatotoxicity. He has research grant support from Gilead, Genfit, Takeda, Cumberland Pharmaceuticals, Intercept pharmaceuticals and Enterome.

\section{Abbreviations}

$\begin{array}{ll}\text { NAFLD } & \text { Nonalcoholic fatty liver disease } \\ \text { CVD } & \text { Cardiovascular disease } \\ \text { CV } & \text { Cardiovascular } \\ \text { NASH } & \text { Nonalcoholic steatohepatitis } \\ \text { MetS } & \text { Metabolic syndrome }\end{array}$


HDL High-density lipoprotein

Non-HDL-C Non-HDL-cholesterol

VLDL Very-low density lipoproteins

LDL Low-density lipoproteins

IDL Intermediate-density lipoproteins

Lp (a) Lipoprotein a FRS: Framingham Risk Score (FRS)

hs-CRP High sensitivity C-reactive protein

HbA1C Glycosylated hemoglobin

\section{References}

1. Browning JD, Szczepaniak LS, Dobbins R, et al. Prevalence of hepatic steatosis in an urban population in the United States: impact of ethnicity. Hepatology. 2004; 40(6):1387-1395. [PubMed: 15565570]

2. Williams CD, Stengel J, Asike MI, et al. Prevalence of nonalcoholic fatty liver disease and nonalcoholic steatohepatitis among a largely middle-aged population utilizing ultrasound and liver biopsy: a prospective study. Gastroenterology. 2011; 140(1):124-131. [PubMed: 20858492]

3. Charlton M. Cirrhosis and liver failure in nonalcoholic fatty liver disease: Molehill or mountain? Hepatology. 2008; 47(5):1431-1433. [PubMed: 18393323]

4. Musso G, Gambino R, Cassader M, Pagano G. Meta-analysis: natural history of non-alcoholic fatty liver disease (NAFLD) and diagnostic accuracy of non-invasive tests for liver disease severity. Ann Med. 2011; 43(8):617-649. [PubMed: 21039302]

5. Dunn W, Xu R, Wingard DL, et al. Suspected nonalcoholic fatty liver disease and mortality risk in a population-based cohort study. Am J Gastroenterol. 2008; 103(9):2263-2271. [PubMed: 18684196]

6. DeFilippis AP, Blaha MJ, Martin SS, et al. Nonalcoholic fatty liver disease and serum lipoproteins: the Multi-Ethnic Study of Atherosclerosis. Atherosclerosis. 2013; 227(2):429-436. [PubMed: 23419204]

7. Toledo FG, Sniderman AD, Kelley DE. Influence of hepatic steatosis (fatty liver) on severity and composition of dyslipidemia in type 2 diabetes. Diabetes Care. 2006; 29(8):1845-1850. [PubMed: 16873790]

8. Speliotes EK, Massaro JM, Hoffmann U, et al. Fatty liver is associated with dyslipidemia and dysglycemia independent of visceral fat: the Framingham Heart Study. Hepatology. 2010; 51(6): 1979-1987. [PubMed: 20336705]

9. Corey KE, Lai M, Gelrud LG, et al. Non-high-density lipoprotein cholesterol as a biomarker for nonalcoholic steatohepatitis. Clin Gastroenterol Hepatol. 2012; 10(6):651-656. [PubMed: 22330232]

10. Robinson JG, Wang S, Smith BJ, Jacobson TA. Meta-analysis of the relationship between nonhigh-density lipoprotein cholesterol reduction and coronary heart disease risk. J Am Coll Cardiol. 2009; 53(4):316-322. [PubMed: 19161879]

11. Arsenault BJ, Rana JS, Stroes ES, et al. Beyond low-density lipoprotein cholesterol: respective contributions of non-high-density lipoprotein cholesterol levels, triglycerides, and the total cholesterol/high-density lipoprotein cholesterol ratio to coronary heart disease risk in apparently healthy men and women. J Am Coll Cardiol. 2009; 55(1):35-41. [PubMed: 20117361]

12. Third Report of the National Cholesterol Education Program (NCEP) Expert Panel on Detection, Evaluation, and Treatment of High Blood Cholesterol in Adults (Adult Treatment Panel III) final report. Circulation. 2002; 106(25):3143-3421. [PubMed: 12485966] 
13. Targher G, Bertolini L, Rodella S, et al. Nonalcoholic fatty liver disease is independently associated with an increased incidence of cardiovascular events in type 2 diabetic patients. Diabetes Care. 2007; 30(8):2119-2121. [PubMed: 17519430]

14. Adams LA, Lymp JF, St Sauver J, et al. The natural history of nonalcoholic fatty liver disease: a population-based cohort study. Gastroenterology. 2005; 129(1):113-121. [PubMed: 16012941]

15. Hamaguchi M, Kojima T, Takeda N, et al. The metabolic syndrome as a predictor of nonalcoholic fatty liver disease. Ann Intern Med. 2005; 143(10):722-728. [PubMed: 16287793]

16. Hamaguchi M, Kojima T, Takeda N, et al. Nonalcoholic fatty liver disease is a novel predictor of cardiovascular disease. World J Gastroenterol. 2007; 13(10):1579-1584. [PubMed: 17461452]

17. Soderberg C, Stal P, Askling J, et al. Decreased survival of subjects with elevated liver function tests during a 28-year follow-up. Hepatology. 2010; 51(2):595-602. [PubMed: 20014114]

18. Ekstedt M, Franzen LE, Mathiesen UL, et al. Long-term follow-up of patients with NAFLD and elevated liver enzymes. Hepatology. 2006; 44(4):865-873. [PubMed: 17006923]

19. Treeprasertsuk S, Leverage S, Adams LA, Lindor KD, St Sauver J, Angulo P. The Framingham risk score and heart disease in nonalcoholic fatty liver disease. Liver Int. 2012; 32(6):945-950. [PubMed: 22299674]

20. Marchesini G, Bugianesi E, Forlani G, et al. Nonalcoholic fatty liver, steatohepatitis, and the metabolic syndrome. Hepatology. 2003; 37(4):917-923. [PubMed: 12668987]

21. Mottillo S, Filion KB, Genest J, et al. The metabolic syndrome and cardiovascular risk a systematic review and meta-analysis. J Am Coll Cardiol. 2010; 56(14):1113-1132. [PubMed: 20863953]

22. Oda E. Metabolic syndrome: its history, mechanisms, and limitations. Acta Diabetol. 2011; 49(2): 89-95. [PubMed: 21720880]

23. Greenland P, Alpert JS, Beller GA, et al. 2010 ACCF/AHA guideline for assessment of cardiovascular risk in asymptomatic adults: a report of the American College of Cardiology Foundation/American Heart Association Task Force on Practice Guidelines. Circulation. 2010; 122(25):e584-e636. [PubMed: 21098428]

24. O'Leary DH, Polak JF, Kronmal RA, Manolio TA, Burke GL, Wolfson SK Jr. Carotid-artery intima and media thickness as a risk factor for myocardial infarction and stroke in older adults. Cardiovascular Health Study Collaborative Research Group. N Engl J Med. 1999; 340(1):14-22. [PubMed: 9878640]

25. Folsom AR, Kronmal RA, Detrano RC, et al. Coronary artery calcification compared with carotid intima-media thickness in the prediction of cardiovascular disease incidence: the Multi-Ethnic Study of Atherosclerosis (MESA). Arch Intern Med. 2008; 168(12):1333-1339. [PubMed: 18574091]

26. Aygun C, Kocaman O, Sahin T, et al. Evaluation of metabolic syndrome frequency and carotid artery intima-media thickness as risk factors for atherosclerosis in patients with nonalcoholic fatty liver disease. Dig Dis Sci. 2008; 53(5):1352-1357. [PubMed: 17939039]

27. Kim D, Choi SY, Park EH, et al. Nonalcoholic fatty liver disease is associated with coronary artery calcification. Hepatology. 2012; 56(2):605-613. [PubMed: 22271511]

28. Fracanzani AL, Burdick L, Raselli S, et al. Carotid artery intima-media thickness in nonalcoholic fatty liver disease. Am J Med. 2008; 121(1):72-78. [PubMed: 18187076]

29. Kirk E, Reeds DN, Finck BN, Mayurranjan SM, Patterson BW, Klein S. Dietary fat and carbohydrates differentially alter insulin sensitivity during caloric restriction. Gastroenterology. 2009; 136(5):1552-1560. [PubMed: 19208352]

30. Tendler D, Lin S, Yancy WS Jr, et al. The effect of a low-carbohydrate, ketogenic diet on nonalcoholic fatty liver disease: a pilot study. Dig Dis Sci. 2007; 52(2):589-593. [PubMed: 17219068]

31. Shai I, Schwarzfuchs D, Henkin Y, et al. Weight loss with a low-carbohydrate, Mediterranean, or low-fat diet. N Engl J Med. 2008; 359(3):229-241. [PubMed: 18635428]

32. Estruch R, Ros E, Salas-Salvado J, et al. Primary prevention of cardiovascular disease with a Mediterranean diet. N Engl J Med. 2013; 368(14):1279-1290. [PubMed: 23432189] 
33. Ryan MC, Itsiopoulos C, Thodis T, et al. The Mediterranean diet improves hepatic steatosis and insulin sensitivity in individuals with non-alcoholic fatty liver disease. J Hepatol. 2013; 59(1):138143. [PubMed: 23485520]

34. Ouyang X, Cirillo P, Sautin Y, et al. Fructose consumption as a risk factor for non-alcoholic fatty liver disease. J Hepatol. 2008; 48(6):993-999. [PubMed: 18395287]

35. Durstine JL, Grandjean PW, Cox CA, Thompson PD. Lipids, lipoproteins, and exercise. J Cardiopulm Rehabil. 2002; 22(6):385-398. [PubMed: 12464825]

36. Wood PD, Haskell WL, Blair SN, et al. Increased exercise level and plasma lipoprotein concentrations: a one-year, randomized, controlled study in sedentary, middle-aged men. Metabolism. 1983; 32(1):31-39. [PubMed: 6848894]

37. St George A, Bauman A, Johnston A, Farrell G, Chey T, George J. Independent effects of physical activity in patients with nonalcoholic fatty liver disease. Hepatology. 2009; 50(1):68-76. [PubMed: 19444870]

38. Johnson NA, Sachinwalla T, Walton DW, et al. Aerobic exercise training reduces hepatic and visceral lipids in obese individuals without weight loss. Hepatology. 2009; 50(4):1105-1112. [PubMed: 19637289]

39. Gunji T, Matsuhashi N, Sato H, et al. Light and moderate alcohol consumption significantly reduces the prevalence of fatty liver in the Japanese male population. Am J Gastroenterol. 2009; 104(9):2189-2195. [PubMed: 19550408]

40. Dunn W, Sanyal AJ, Brunt EM, et al. Modest alcohol consumption is associated with decreased prevalence of steatohepatitis in patients with non-alcoholic fatty liver disease (NAFLD). J Hepatol. 2012; 57(2):384-391. [PubMed: 22521357]

41. Botros N, Concato J, Mohsenin V, Selim B, Doctor K, Yaggi HK. Obstructive sleep apnea as a risk factor for type 2 diabetes. Am J Med. 2009; 122(12):1122-1127. [PubMed: 19958890]

42. Ip MS, Lam B, Ng MM, Lam WK, Tsang KW, Lam KS. Obstructive sleep apnea is independently associated with insulin resistance. Am J Respir Crit Care Med. 2002; 165(5):670-676. [PubMed: 11874812]

43. Mooe T, Franklin KA, Holmstrom K, Rabben T, Wiklund U. Sleep-disordered breathing and coronary artery disease: long-term prognosis. Am J Respir Crit Care Med. 2001; 164(10 Pt 1): 1910-1913. [PubMed: 11734445]

44. Gami AS, Howard DE, Olson EJ, Somers VK. Day-night pattern of sudden death in obstructive sleep apnea. N Engl J Med. 2005; 352(12):1206-1214. [PubMed: 15788497]

45. Steiropoulos P, Tsara V, Nena E, et al. Effect of continuous positive airway pressure treatment on serum cardiovascular risk factors in patients with obstructive sleep apnea-hypopnea syndrome. Chest. 2007; 132(3):843-851. [PubMed: 17573492]

46. Harsch IA, Schahin SP, Radespiel-Troger M, et al. Continuous positive airway pressure treatment rapidly improves insulin sensitivity in patients with obstructive sleep apnea syndrome. Am J Respir Crit Care Med. 2004; 169(2):156-162. [PubMed: 14512265]

47. Savransky V, Bevans S, Nanayakkara A, et al. Chronic intermittent hypoxia causes hepatitis in a mouse model of diet-induced fatty liver. Am J Physiol Gastrointest Liver Physiol. 2007; 293(4):G871-G877. [PubMed: 17690174]

48. Savransky V, Nanayakkara A, Vivero A, et al. Chronic intermittent hypoxia predisposes to liver injury. Hepatology. 2007; 45(4):1007-1013. [PubMed: 17393512]

49. Aron-Wisnewsky J, Minville C, Tordjman J, et al. Chronic intermittent hypoxia is a major trigger for non-alcoholic fatty liver disease in morbid obese. J Hepatol. 2012; 56(1):225-233. [PubMed: 21703181]

50. Shpirer I, Copel L, Broide E, Elizur A. Continuous positive airway pressure improves sleep apnea associated fatty liver. Lung. 2010; 188(4):301-307. [PubMed: 20066542]

51. Gaede P, Vedel P, Larsen N, Jensen GV, Parving HH, Pedersen O. Multifactorial intervention and cardiovascular disease in patients with type 2 diabetes. N Engl J Med. 2003; 348(5):383-393. [PubMed: 12556541]

52. Kooy A, de Jager J, Lehert P, et al. Long-term effects of metformin on metabolism and microvascular and macrovascular disease in patients with type 2 diabetes mellitus. Arch Intern Med. 2009; 169(6):616-625. [PubMed: 19307526] 
53. Athyros VG, Tziomalos K, Gossios TD, et al. Safety and efficacy of long-term statin treatment for cardiovascular events in patients with coronary heart disease and abnormal liver tests in the Greek Atorvastatin and Coronary Heart Disease Evaluation (GREACE) Study: a post-hoc analysis. Lancet. 2010; 376(9756):1916-1922. [PubMed: 21109302]

54. Foster T, Budoff MJ, Saab S, Ahmadi N, Gordon C, Guerci AD. Atorvastatin and antioxidants for the treatment of nonalcoholic fatty liver disease: the St Francis Heart Study randomized clinical trial. Am J Gastroenterol. 2011; 106(1):71-77. [PubMed: 20842109]

55. Ekstedt M, Franzen LE, Mathiesen UL, Holmqvist M, Bodemar G, Kechagias S. Statins in nonalcoholic fatty liver disease and chronically elevated liver enzymes: a histopathological follow-up study. J Hepatol. 2007; 47(1):135-141. [PubMed: 17400325]

56. Hyogo H, Yamagishi S, Maeda S, Kimura Y, Ishitobi T, Chayama K. Atorvastatin improves disease activity of nonalcoholic steatohepatitis partly through its tumour necrosis factor-alphalowering property. Dig Liver Dis. 2012; 44(6):492-496. [PubMed: 22265683]

57. Athyros VG, Mikhailidis DP, Didangelos TP, et al. Effect of multifactorial treatment on nonalcoholic fatty liver disease in metabolic syndrome: a randomised study. Curr Med Res Opin. 2006; 22(5):873-883. [PubMed: 16709309]

58. Nelson A, Torres DM, Morgan AE, Fincke C, Harrison SA. A pilot study using simvastatin in the treatment of nonalcoholic steatohepatitis: A randomized placebo-controlled trial. J Clin Gastroenterol. 2009; 43(10):990-994. [PubMed: 19448566]

59. El-Serag HB, Johnson ML, Hachem C, Morgana RO. Statins are associated with a reduced risk of hepatocellular carcinoma in a large cohort of patients with diabetes. Gastroenterology. 2009; 136(5):1601-1608. [PubMed: 19208359]

60. Vuppalanchi R, Chalasani N. Statins for hyperlipidemia in patients with chronic liver disease: are they safe? Clin Gastroenterol Hepatol. 2006; 4(7):838-839. [PubMed: 16829348]

61. Vuppalanchi R, Chalasani N. Nonalcoholic fatty liver disease and nonalcoholic steatohepatitis: Selected practical issues in their evaluation and management. Hepatology. 2009; 49(1):306-317. [PubMed: 19065650]

62. Chalasani N. Statins and hepatotoxicity: focus on patients with fatty liver. Hepatology. 2005; 41(4):690-695. [PubMed: 15789367]

63. Cohen DE, Anania FA, Chalasani N. An assessment of statin safety by hepatologists. Am J Cardiol. 2006; 97(8A):77C-81C. [PubMed: 16377288]

64. Chalasani N, Aljadhey H, Kesterson J, Murray MD, Hall SD. Patients with elevated liver enzymes are not at higher risk for statin hepatotoxicity. Gastroenterology. 2004; 126(5):1287-1292. [PubMed: 15131789]

65. Lewis JH, Mortensen ME, Zweig S, Fusco MJ, Medoff JR, Belder R. Efficacy and safety of highdose pravastatin in hypercholesterolemic patients with well-compensated chronic liver disease: Results of a prospective, randomized, double-blind, placebo-controlled, multicenter trial. Hepatology. 2007; 46(5):1453-1463. [PubMed: 17668878]

66. Wang C, Harris WS, Chung M, et al. n-3 Fatty acids from fish or fish-oil supplements, but not alpha-linolenic acid, benefit cardiovascular disease outcomes in primary- and secondaryprevention studies: a systematic review. Am J Clin Nutr. 2006; 84(1):5-17. [PubMed: 16825676]

67. Harris WS. n-3 fatty acids and serum lipoproteins: human studies. Am J Clin Nutr. 1997; 65(5 Suppl):1645S-1654S. [PubMed: 9129504]

68. Cussons AJ, Watts GF, Mori TA, Stuckey BG. Omega-3 fatty acid supplementation decreases liver fat content in polycystic ovary syndrome: a randomized controlled trial employing proton magnetic resonance spectroscopy. J Clin Endocrinol Metab. 2009; 94(10):3842-3848. [PubMed: 19622617]

69. Spadaro L, Magliocco O, Spampinato D, et al. Effects of n-3 polyunsaturated fatty acids in subjects with nonalcoholic fatty liver disease. Dig Liver Dis. 2008; 40(3):194-199. [PubMed: 18054848]

70. Zhu FS, Liu S, Chen XM, Huang ZG, Zhang DW. Effects of n-3 polyunsaturated fatty acids from seal oils on nonalcoholic fatty liver disease associated with hyperlipidemia. World J Gastroenterol. 2008; 14(41):6395-6400. [PubMed: 19009658] 
71. Pierce LR, Wysowski DK, Gross TP. Myopathy and rhabdomyolysis associated with lovastatingemfibrozil combination therapy. Jama. 1990; 264(1):71-75. [PubMed: 2355431]

72. Athyros VG, Papageorgiou AA, Hatzikonstandinou HA, et al. Safety and efficacy of long-term statin-fibrate combinations in patients with refractory familial combined hyperlipidemia. Am J Cardiol. 1997; 80(5):608-613. [PubMed: 9294990]

73. Fernandez-Miranda C, Perez-Carreras M, Colina F, Lopez-Alonso G, Vargas C, Solis-Herruzo JA. A pilot trial of fenofibrate for the treatment of non-alcoholic fatty liver disease. Dig Liver Dis. 2008; 40(3):200-205. [PubMed: 18261709]

74. Laurin J, Lindor KD, Crippin JS, et al. Ursodeoxycholic acid or clofibrate in the treatment of nonalcohol-induced steatohepatitis: a pilot study. Hepatology. 1996; 23(6):1464-1467. [PubMed: 8675165]

75. Canner PL, Berge KG, Wenger NK, et al. Fifteen year mortality in Coronary Drug Project patients: long-term benefit with niacin. J Am Coll Cardiol. 1986; 8(6):1245-1255. [PubMed: 3782631]

76. Akdim F, Tribble DL, Flaim JD, et al. Efficacy of apolipoprotein B synthesis inhibition in subjects with mild-to-moderate hyperlipidaemia. Eur Heart J. 2011; 32(21):2650-2659. [PubMed: 21593041]

77. Akdim F, Visser ME, Tribble DL, et al. Effect of mipomersen, an apolipoprotein B synthesis inhibitor, on low-density lipoprotein cholesterol in patients with familial hypercholesterolemia. Am J Cardiol. 2010; 105(10):1413-1419. [PubMed: 20451687]

78. Visser ME, Wagener G, Baker BF, et al. Mipomersen, an apolipoprotein B synthesis inhibitor, lowers low-density lipoprotein cholesterol in high-risk statin-intolerant patients: a randomized, double-blind, placebo-controlled trial. Eur Heart J. 2012; 33(9):1142-1149. [PubMed: 22507979]

79. Cuchel M, Meagher EA, du Toit Theron H, et al. Efficacy and safety of a microsomal triglyceride transfer protein inhibitor in patients with homozygous familial hypercholesterolaemia: a singlearm, open-label, phase 3 study. Lancet. 2013; 381(9860):40-46. [PubMed: 23122768]

80. Cuchel M, Bloedon LT, Szapary PO, et al. Inhibition of microsomal triglyceride transfer protein in familial hypercholesterolemia. N Engl J Med. 2007; 356(2):148-156. [PubMed: 17215532]

81. Haring R, Volzke H, Felix SB, et al. Prediction of metabolic syndrome by low serum testosterone levels in men: results from the study of health in Pomerania. Diabetes. 2009; 58(9):2027-2031. [PubMed: 19581420]

82. Schwimmer JB, Deutsch R, Kahen T, Lavine JE, Stanley C, Behling C. Prevalence of fatty liver in children and adolescents. Pediatrics. 2006; 118(4):1388-1393. [PubMed: 17015527]

83. Dam-Larsen S, Becker U, Franzmann MB, Larsen K, Christoffersen P, Bendtsen F. Final results of a long-term, clinical follow-up in fatty liver patients. Scand J Gastroenterol. 2009; 44(10):12361243. [PubMed: 19670076]

84. Rafiq N, Bai C, Fang Y, et al. Long-term follow-up of patients with nonalcoholic fatty liver. Clin Gastroenterol Hepatol. 2009; 7(2):234-238. [PubMed: 19049831] 


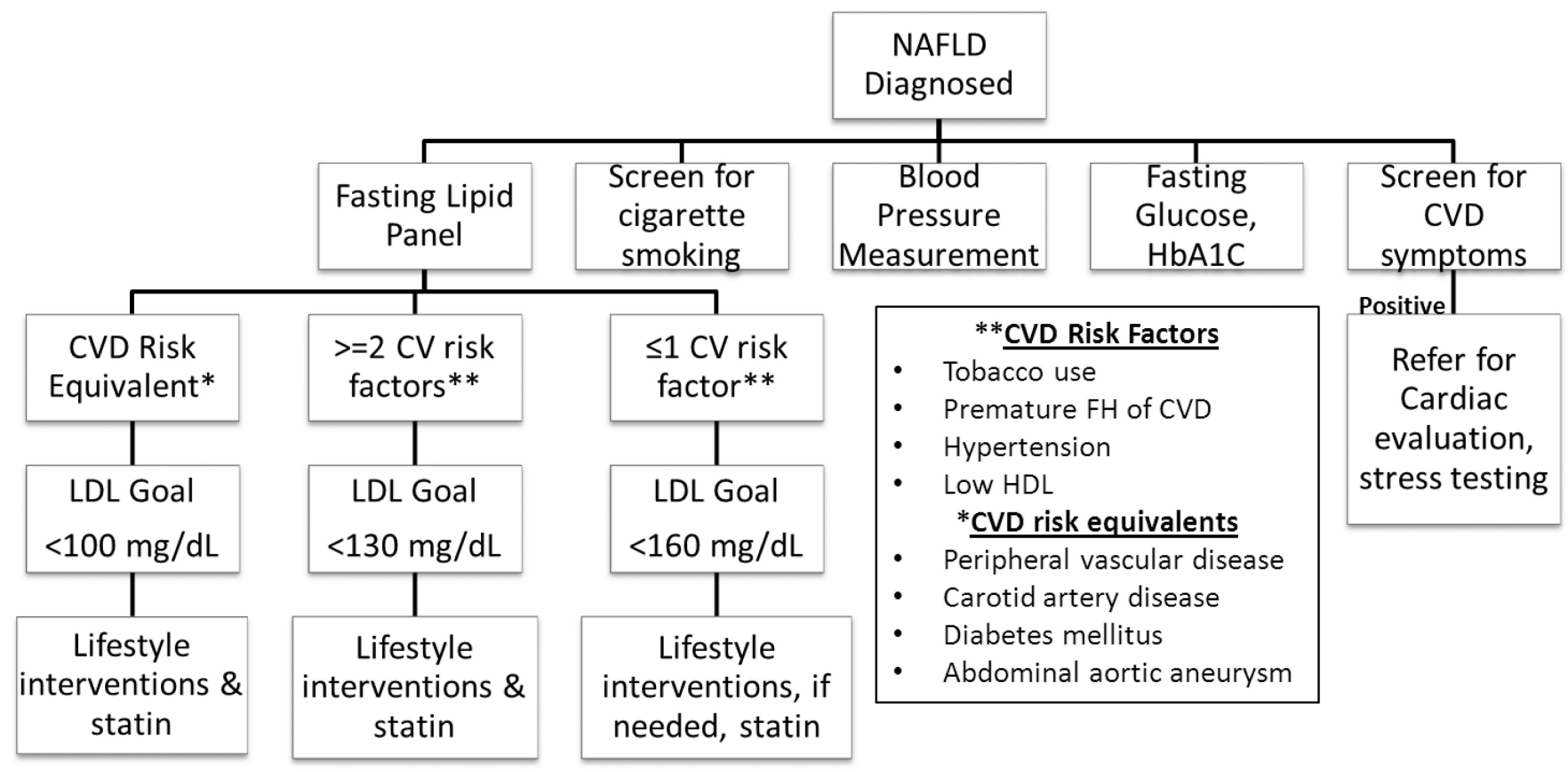

Figure 1.

Cardiovascular Risk Assessment in NAFLD

*Adapted from the National Cholesterol Education Program ATP III Guidelines

NAFLD: non-alcoholic fatty liver disease, HbA1C: glycosylated hemoglobin, CVD:

cardiovascular disease, LDL: low density lipoprotein, FH family history, HDL: high density lipoprotein 


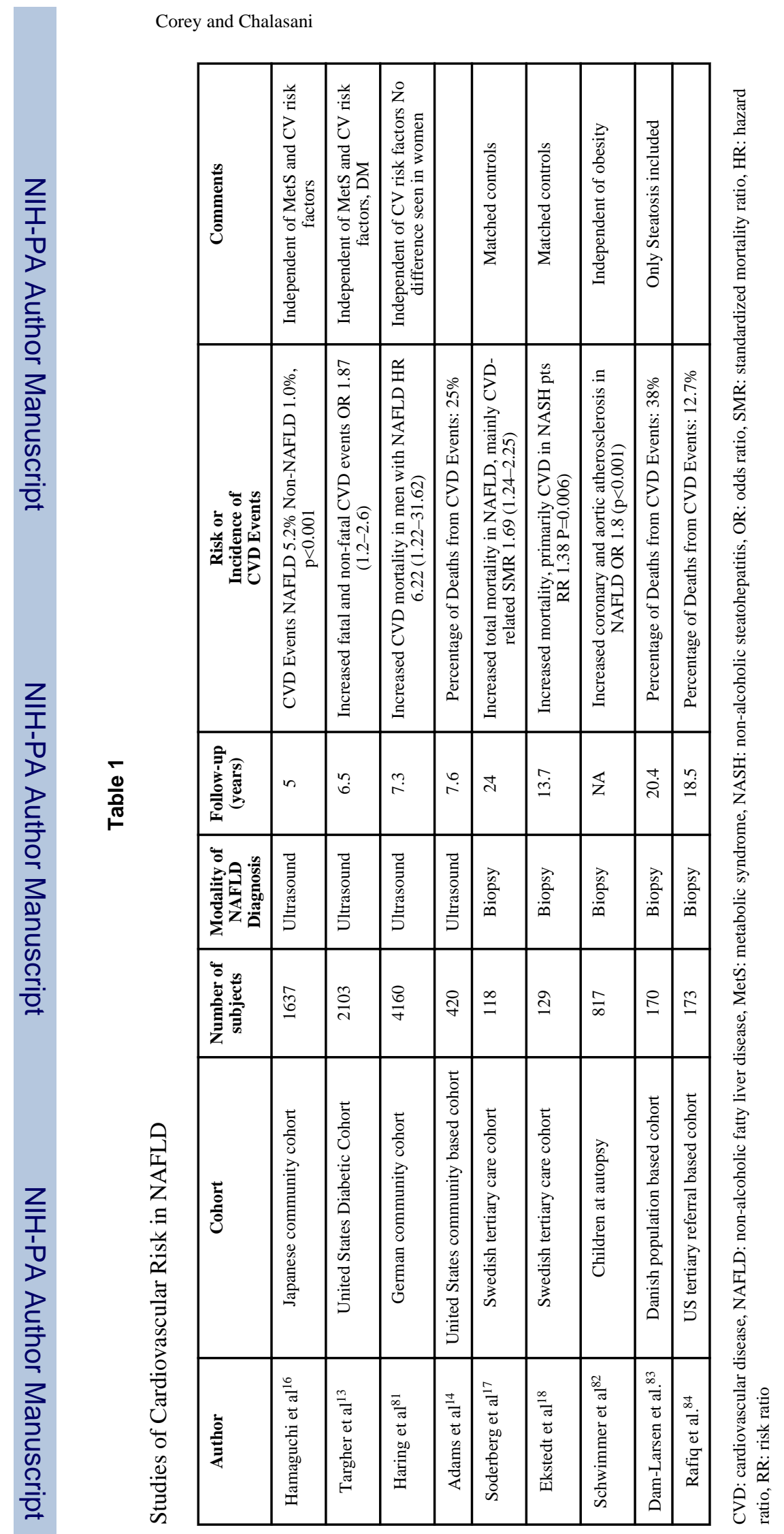

Page 15 